\title{
We like... cultural traits in cyberculture
}

\author{
G. Fletcher ${ }^{1} \&$ A. Greenhill ${ }^{2}$ \\ ${ }^{1}$ Information Systems Institute, University of Salford, UK \\ ${ }^{2}$ Manchester Business School, Manchester University, UK
}

\begin{abstract}
This paper critically identifies a series of traits that are representative of contemporary cyberculture(s). From this identification the paper considers the way in which these traits - as they are specifically articulated in the spaces of the World Wide Web - enables the articulation of social solidarity through the continuous synthesis of conflict and conformity. A key claim is that cyberculture is not immune from the practices of conflict and aggression found elsewhere in 'everyday life'. Effacing, or attempting to efface, these practices from a virtual provenance is argued to be a fraught agenda that ignores the ways that aggression promotes solidarity. This paper draws upon the empirical evidence of popular Web search terms to reveal the popularity and persistence of interest in a relatively small set of activities and 'things'. A series of cultural traits are then consequently identified as being general preferences for freeness, participation, customisation, perversion and anonymity. These traits find expression within an information-rich environment that supports acts of conflict while also enabling expressions of conformity. The paper concludes with the observation that conflict and conformity are bound in a dialectic relationship that supports continuous (cyber)cultural dynamism and change.
\end{abstract}

Keywords: cultural traits, solidarity, conformity, conflict, cyberculture, webbased search, information rich environment, everyday life.

\section{Introduction: cyberculture and everyday life}

\subsection{Introduction}

This paper draws upon a series of 'classic' social science concepts and understandings to critically position the notion and meanings of cyberculture. The use of 'traditional' concepts reflects the central position of this paper that 
cyberculture is not distinct from the practices of everyday life and is increasingly a synonym for mainstream culture [1]. This tight association is relevant irrespective of individual access opportunities to the Internet as cyberculture is not bound to the arbitrary boundaries of the 'virtual'. Popular Web search terms are utilised as a source of empirical evidence for this discussion with the understanding that the use of search engines are not restricted to a particular subculture or ethnic group. In other words, popular search engines are seen to reflect current mainstream interests, concerns and desires and cannot be condemned to 'merely' being the domain of ill-defined and indefinite subcultures such as 'geeks'. The specific technologies and qualities of Web use, however, may quantitatively distort these interests in particular directions. This influence is acknowledged with the examination of these terms within the interpretive framework of generalised 'traits' rather than as a definitive positivistic reality.

Discussions of conflict and conformity contrast with the more recent and extensive use of 'trust' to position discussions of cyberculture and Web-based interactions (e.g. [2]). 'Trust', it is critically claimed, is more readily identified as the appellation for an information management technique than as observable sociological phenomena [3]. The argument here, in drawing upon Collins [4] discussion of the September 11 terrorist attacks, is that solidarity is the synthesis of acts of conflict and conformity that are enabled by the dominant traits of mainstream (cyber)culture. Conflict is not presented here with a prejudgement of negativity but is instead seen as an antithesis to conformity. When brought together the interaction of conflictual 'strange attractors' and mainstream power structures [5] produce unifying (although perhaps brief) moments of solidarity.

\subsection{Defining cyberculture}

Penley and Ross [6] utilised the term, technoculture, in one of the first collections in this area of research. Since this early work other commentators have opted for various - sometimes more specialised - terms such as cybersociety [7], virtual communities [8] and virtual society [9]. Each of these terms reflects a particular bias, preference and moment in the movement towards a coherent body of research. Cyberculture is used here to reinforce the cultural focus of this discussion and the fact that this expresses concern for particular (but admittedly broad) aspects of human experience.

The description, 'cyberculture', is also used to indicate its close association with, rather than distinction from, mainstream cultural practice. In this sense cyberculture is the identification of one point in an historical continuity of mainstream contemporary cultures that incorporates - as a central feature - the accelerated and pervasive use of information and communication technologies [10]. It is important to stress that this definition also emphasises the negotiated nature of culture and does not imply that cyberculture is 'just' the deterministic consequence of particular technologies.

The use of the term 'culture' also introduces the complexities of its definition. Williams [11] described 'culture' as "one of the two or three most complex words in the English language" while Geertz [12] identified eleven variations in 
meanings before contributing his own additional definition. Sahlins [13] assumed the more pragmatic view that,

culture as a design for society's continuity, stipulates its environment. By its mode of production, by the material requirements of its social structure, in its standardised perceptions, a culture assigns relevance to particular external conditions...There is an interchange between culture and environment, perhaps continuous dialectic interchange.

While Sahlins' discussion is focused on traditional lifeways a very similar claim can be made for the contemporary 'high technology', information-rich environment of cyberculture.

\subsection{The information rich environment}

The information rich environment of mainstream cyberculture stimulates both conflict and conformity. Its experience is not restricted to a virtual provenance and is another indication of the pervasiveness of cyberculture beyond direct computer access. In this environment expressions of conflict and conformity are stored and can be retrieved almost indefinitely enabling individual comments to be reproduced and referred to beyond the lifespan of traditional discourse. The longevity that information richness provides is balanced with its immediacy. The kidnapping and release of a BBC journalist can occur in a single day and be reported simultaneously ( $13^{\text {th }}$ August 2004). The information rich environment of cyberculture also has a density of information that ensures, for example, that almost any search term - including all the most popular terms - will inevitably produce a list of results. Longevity, immediacy and density of information all contribute to a blurring of cultural boundaries and physical delimitation of cultural practice.

This environment also enables a clear articulation of identifiable traits within contemporary cyberculture. This is a result of the capacities of this environment, including its longevity, immediacy and density, and not because 'less' or 'fewer' traits were present in earlier mainstream cultures. The distinction is based upon the visibility of traits rather than some form of previous impoverishment. Each trait benefits from the density and variety of information found in this environment which, in turn, accentuates their visibility. It is these qualities that provide the capacity for the Internet to be a social laboratory - for the researcher - to a broad set of practices.

While the recent terrorist attacks of 2001, 2003 and 2004 have generated significant amounts of academic interpretation (e.g. [14]) this belies the degree to which conflict, conformity and solidarity have been central areas of concerns for social scientists throughout most of the previous century. Away from the emotive responses of the most recent works, the social science tradition in this area offers a substantial body of theorisation that has relevance to the examination of contemporary cyberculture. The focus on specific acts of terrorism has obscured its role as an organisation tactic [15] rather than a specific philosophy or political agenda. The emotive discussions of recent attacks also disentangles terrorism (and its extreme violence) from other forms of more 
'mundane' conflict and the increasing use of the information rich environment to exchange in various forms of information warfare.

\section{Identifying cultural traits}

\subsection{Utilising cultural traits as an analytical tool}

Identifying a series of prevailing mainstream cultural traits through the Web provides opportunity for consideration of this culture as a collectivity of interrelated human experiences rather than a series of discrete (Web) sites or monolithic culture. De Certeau [16] expresses this concern as the marginality of the majority,

Marginality is today no longer limited to minority, but is rather massive and pervasive; this cultural activity of the non-producers of culture, an activity that is unsigned, unreadable and unsymbolized, remains the only one possible for all those who nevertheless buy and pay for the showy products through which a productivist economy articulates itself.

Cultural traits are identifiable in the observation of everyday life through their persistence, repetition, popularity and general recognisability. Many traits are taken for granted and even disregarded for their significance, for example, human sleep ecologies and food preferences. Other traits shift over time and become the source of note such as the increasing rejection of cricket as 'the' sport of the West Indies [17]. Cultural traits like culture itself have been defined in various ways to suit many purposes. Their use is most commonly found in relation to archaeological artefacts where the reconstruction of a cultural complex can only be inferred from material remains. Considered in combination associated traits and artefacts constitute a cultural complex. In contemporary culture this cultural complex is 'our' everyday life. This proximity to the traits and artefacts that are all around 'us' obscures 'our' ability to recognise these qualities. Search terms provide sufficient distanciation from the immediacy of this information rich information to enable theoried identification.

Interpretation of cultural traits has been criticised as an unnecessary and artificial approach to understanding culture [18]. Aunger [18] argues that, "seeing culture as an integrated whole that transcends the minds of individuals is analytically barren, since there is no contesting a representation that is built up by the imagination of the ethnographer." This paper actively engages with the "minds of individuals" in their expression of individual search terms.

Each search term, each weekly collection of terms and the repetition of the same terms from week to week 'speak' to us and from this 'speech' the observer can garner some understanding of the culture(s) that produced and utilised the individual term [19]. Search terms - as artefacts of the culture that produced them - are cultural items and simultaneously they are reflections of culture [20]. Extending this argument further this paper claims that interpreting the seeking and desire for artefacts represented in each search term also reveals the cultural traits with which these artefacts interact, intersect and are integral components. "The thin film of writing becomes a movement of strata, a play of spaces. A 
different world (the reader) slips into the author's place" [16]. Prown [21] concurs by claiming that "the quest is not to gather information about the object itself and the activities and practices of the society that produced it, but rather to discover underlying cultural beliefs." The sentiments of that project are pursued here in order to identify dominant cultural traits that are discernible amongst the gathered search terms.

\subsection{Defining cultural traits}

The gathered search terms indicate the presence of five predominant traits of contemporary cyberculture. These traits are discernable not only in the gathered data itself but can also be confirmed through mass media reports and other systematic observations of this culture. The five traits are defined here as a set of cultural practices and attitudes that are represented as desires for freeness, participation, customisation, anonymity and perversion. This is not a definitive summation of all the gathered search terms and not all the gathered search terms can be readily associated with these traits. However, the 'core' most popular and regular search terms are readily identified with at least one of these traits. The importance of these five particular traits is not that they can be consistently identified in the gathered search term data but the degree to which they epitomise central sentiments and attitudes of contemporary cyberculture.

\subsection{Web search terms as a reflection of cultural practice}

Information about the popularity of search terms is drawn from the "Top 500 Search Terms" newsletters over a period of 16 months from September 2001. The terms were consistently classified using the Universal Decimal Classification system. The advantage of a decimal classifactory taxonomy is its capacity to reveal groupings of search terms at differing levels of magnification. This magnification shifts from the coarsest top level classes containing only nine categories to the potential minutae of nine hundred third level classes and the use of decimal points that offer the capacity for still further divisions. Universial Decimal Classification also enables the grouping and association of multiple classes together. However, the purpose of constructing a taxonomy of search terms was to group rather than separate 'like' terms in order to identify the themes - and ultimately the traits - of the culture generating the individual searches. The weekly newsletter of popular search terms provided sets of both 'surge' and 'consistent' search terms. The 'surge list' includes the most popular terms of the previous 24 hours while the 'consistent list' showed the popular terms over the last four weeks. These lists can differ dramatically within the same week. Both lists, it should be noted, also incorporate 'adult' terms as they are effectively uncensored.

Classifying search terms brings together conceptually associated terms that appear separately in a variety of forms throughout the weekly lists. The most conspicuous duplications in the original lists of terms are found in variations of domain names. For example in both sets of weekly lists, 'yahoo', 'yahoo.com' and 'www.yahoo.com' all consistently appear as separate terms but in a 
classificatory sense they are unambiguously a single item. Similarly 'google', 'google.com' and 'www.google.com' hold a single meaning. Considering these terms together, as representing a similar consistent meaning and intent for searchers, has the impact of making 'yahoo' one of the most regularly searched for terms in the weekly list - rather than 'sex' as is popularly claimed [22]. However, in most other situations search terms represent conceptually separate entities despite a classificatory closeness. For example - in the consistent list of the $22^{\text {nd }}$ February 2003, 'song lyrics' (26th), 'music' (31st) and 'Free Download Music' (61st) are associated terms. The Universal Decimal Classification scheme associates them by sufficient proximity to reflect a related intent and meaning within the top-level class of Arts and Entertainment.

Consistent classification of popular search terms reveals a relatively narrow range of interests. This is revealed in the 'grouping' of terms around a small set of classifactory classes. The clustering of search terms is best revealed in the variety of pornographic Web sites and individual actors or musicians that resolve to only three separate third level classes. With two of these examples (pornography and musicians) these classificatorily 'like' set of terms are the almost exclusive representatives of their respective top level (and broadest) classes. Within the Psychology class, 65 of the 75 terms represent some form of pornography.

The classification process itself does not directly define or locate particular cultural traits of contemporary cyberculture. Each trait can, however, be identified as a consequence of the process of classification. The desire for freeness can be directly seen in the vast range of search terms (97 individual search terms and fluctuating between $6 \%$ and $10 \%$ of all the classified searches) that incorporate this word. Similarly perversion can be readily identified through the vast collection of individual pornographic Web sites, generic sexual descriptions and proclivities that are scattered throughout the classified search terms. Other forms of perversion are also represented including fascination in the details of shocking murders (such as 'Klingle Mansion') and individual Web sites that offer suicide and autopsy images. Traits of participation, customisation and anonymity are less readily identified in individual search terms. However, considered in combination and across the collected lists of terms these traits can also be identified. For example, the desire for participation is directly implied with searches for chat rooms. Other terms also suggest action, from the mundane 'pumpkin carving' and 'send flowers' through the predictable 'download music' to the slightly disturbing but more tentative 'nudism', 'masturbation' and 'underagesex'. Preferences for customisation and anonymity can also be identified at this variety of levels.

\section{Everyday life, conflict, cultural traits}

\subsection{The culture of everyday life}

Contemporary cyberculture is hallmarked by the regular intersection of 'strange attractors' with mainstream interests [5] irrespective of the basis for this 
attraction. The result is a panopoly of moments that compete for attention with those that have just passed and those that are yet to become. This produces juxtapositions that can also be identified in the gathered search terms where, for example, the September 11 terrorist attacks 'competes' with Halloween and Christmas celebrations as well as the weekly American Idol reality television programme. A year later the anniversary of the attacks also became a 'strange attractor' to mainstream cyberculture.

Each strange attractor is outside the routine of everyday life, individually distinct (perhaps necessarily so) and not generally comparable at the level of direct microanalysis. This shifting attention in mainstream interest reflects the constant interplay between conflict and conformity within the information rich environment. The synthesis of this interplay includes moments of heightened social solidarity. The sequence of events after the September 11 attacks are the most dramatic example of this synthesis with a swing from a conflictually oriented attractor to an upswing (in the US as well as elsewhere) of patriotic fervour and a widened sense of solidarity [4]. This cultural change can be seen in the search term evidence as a shift in popularity from 'Osama bin Laden' to 'US Flags'. This response lasted briefly and gave way to a new response after the US government's announcements of a "war on terror". Terrorist attacks, television series, individual murders (Daniel Pearl, Klingle Mansion) and annual holidays are 'big' attractors that produce large-scale responses including heightened popularity as a search term. Other attractors are less visible, this is a result of the list of gathered search terms only tracking the most popular terms. Significantly, at least in the context of this argument, the source of attraction can be understood in relation to particular traits and the specific qualities of the information rich environment. The September 11 attacks resulted in heightened numbers of Web searches for news sources suggesting that individuals became their own 'reporter' to this moment of conflict. The customisation of news is a capacity that is accentuated in cyberculture's information rich environment and reveals how the attraction of the September 11 attacks produced an immediate but subtle shift within mainstream power structures - in this case the authority of mass media.

\subsection{Connecting cultural traits and cyberculture}

The identification of cultural traits within the framework of cyberculture provides an analytical framework for interpretation that reflects the dynamic and indefinite forms of culture. Because cultural traits indicate tendencies and preferences rather than certainties or mutually shared commonalities this approach has been criticised. The use of traits here is justified by the globalised and dispersed features of cyberculture that is enabled by the complex environments in which it is enacted. The technologies employed by this culture allows for geographic dispersal with only minimal lose in the capacity to communicate and interact. Arguably, no analytical device is capable of showing an entirely 'true' representation of a culture let alone this culture that is enacted in an information rich and globalised environment. 
Other mechanisms for analysing cyberculture - in its many descriptive guises - have been forced to restrict observation to a single ethnographic 'site'; for example, a Web-based community [3], an organisation [2] or a newsgroup [6]. As these examples reveal, there is a danger of equating cyberculture solely with online environments. These approaches also face the same criticisms levelled at 'urban anthropologists' of the 1960s. Fox [23], in speaking of this older research paradigm claimed that "this specifies more clearly where one locates for research rather than what conceptual goals lie behind this choice of location." A concern that can also be expressed towards at least the first generation of 'cyber' researchers.

Cultural traits offer perspective of a 'whole' culture - in all its imprecision without overly extrapolating from a single 'site' or attempting to commonly assign the same qualities to all its participants. This paper's focus on the relationship between conflict and conformity is only one aspect of cyberculture that can be found in the critical identification and examination of its traits.

\section{Conclusion: cultural dynamism and change}

The interplay of conflict and conformity can also be identified at the scale of Web-based communities where 'Big Men' (long term and respected group members) compete to maintain this position while others seek to draw this status to themselves [3]. Conflict is balanced by messages of support from individuals that produces short-term group stability. The traits of contemporary cyberculture support and reinforce this focus of contemporary cultural activity around 'strange attractors' [5]. The desire for anonymity enables acts of cunning and 'sorcery' that range from the mundane act of identity theft in a chat group [3] to the planning of large scale terrorist acts [14]. Preferences for participation and do-it-yourself can be identified in search terms as the desire to customise computers and download music files but it is also reflected more broadly in the popularity for 'reality television' formats and SMS text polls and competitions. These activities offer a sense of solidarity through participation in mainstream media. Children's television is the most noticeable advocate of this solidarity with various forms of 'membership'. The BBC's Xchange programme invites children to send in photographs that are then stitched in three dimensional "X Heads" which then are animated and speak on screen. The 'perverse' nature of contemporary cyberculture incorporates aspects of both conflict and solidarity. The illicit and illegal nature of many perverse interests that are expressed in popular search terms, and particularly incest, bestiality and paedophilia, encourage a form of 'silent solidarity' through file sharing software. However, the density of online perversion is clearly a point of contention in relation to the impact of pornography and the 'freedom of expression' right that is often invoked in these debates.

Contemporary cyberculture is ultimately a mainstream culture. As with any culture it must change and respond to its environment and shifting preferences, attitudes and traits. The inability to change is arguably a terminal inability [13]. These observations, however, are equally applicable to any modern or traditional 
culture that has previously received theoried consideration. Contemporary cyberculture's difference (and one of its defining features) is its focus and orientation around individual predictable (such as Christmas) and unpredictable (such as terrorist attacks) 'strange attractors' to mainstream systems of power [5]. The meeting of the mainstream with these moments of conflict and tension produce change; albeit potentially small and short-lived change. Identifying the source of these changes and documenting their relationship and impact upon systems of power has been a traditionally difficult task within social science research. However, the information rich environment as the medium for the articulation of this culture also enables it immediate (potentially real-time) examination.

Search terms are indicators and expressions of moments of conflict and conformity within contemporary cyberculture. The change that is invoked by their interaction can also be identified through the rise in popularity of individual search terms. As one result of the negotiation of conflict and conformity the first anniversary of the September 11, 2001 attacks is among the most visible moment in the collected lists of search terms. This anniversary also reveals the dialectical relationship of events to mainstream sentiments. The anniversary of September 11 did not revisit the fear of the attacks but was a new event in its own right that embedded within it the sublimation of these previous events with other sentiments of mainstream cyberculture.

\section{References}

[1] Tomas, D. Old Ritual for New Spaces, Cyberspace: First Steps, (ed) M. Benedikt, The MIT Press: Cambridge MA, 1991.

[2] Jarvenpaa, S., Tractinsky, N. \& Vitale, M. Consumer Trust in an Internet Store. Information Technology and Management Journal, 1(1-2), 45-71, 2000.

[3] Greenhill, A. Campbell, J. \& Fletcher, G. Tribalism and Conflict: Conflict as a social unifier in a technologically enabled community Proceedings of the Eighth Americas Conference on Information Systems, (eds) J. DeGross \& R. Ramsower, Dallas, Texas, 9-11 August, 1634-1644. 2002

[4] Collins, R. Rituals of Solidarity and Security in the Wake of the Terrorist Attack, Sociological Theory, 22(1), March, 53-87, 2004

[5] Urry, J. The Global Complexities of September 11th, Theory, Culture \& Society, 19(4), 57-69, 2002.

[6] Penley, C. and Ross, A. (eds) Technoculture, University of Minnesota Press: Minneapolis, 1991

[7] Jones, S. (eds) CyberSociety: Computer-Mediated Communication and Community, Sage Publications: London, 1995

[8] Wellman, B. and Gulia, M. Net Surfers don't ride alone: virtual communities as communities Communities and Cyberspace, (eds) P. Kollock and M. Smith, Routledge: New York, 1999.

[9] Woolgar, S. Virtual Society? Get real: the social science of electronic technologies, Oxford University Press: Oxford, 2002 
[10] Castells, M. The Internet Galaxy: Reflections on the Internet, Business and Society, Oxford University Press: Oxford, 2001

[11] Williams, R. Keywords: A vocabulary of culture and society, Fontana: London, 1983

[12] Geertz, C. The Interpretation of Culture: Selected Essays, Fontana: London, 1993 [1973].

[13] Sahlins, M. Culture and Environment Horizons of Anthropology, (eds) S. Tax \& L. Freeman, Aldine Publishing Company, Chicago, 1977.

[14] Tilly, C. Terror, Terrorism, Terrorists, Sociological Theory, 22(1), 5-13, 2004.

[15] Gibbs, J. Conceptualisations of Terrorism, American Sociological Review, 54, June, 329-340, 1989

[16] de Certeau, M. The Practice of Everyday Life, S. Rendall (trs), University of California Press: Berkeley, 1988

[17] BBC Story of Cricket Part IV: West Indies, http://news.bbc.co.uk/sport2/hi/cricket/3433735.stm, 2004

[18] Aunger, R. Cultural transmission and diffusion Encyclopedia of Cognitive Science,(ed) L. Nadel, MacMillan: London, http://www.cus.cam.ac.uk / rva20/EncyclCogSci.pdf.

[19] Richardson, M. The Artefact as Abbreviated Act: A Social Interpretation of Material Culture, The Meaning of Things: material culture and symbolic expression, (ed) I. Hodder, HarperCollins Academic: London, 1989.

[20] Nguyen, D. and Alexander, J. The Coming of Cyberspacetime and the End of the Polity Cultures of Internet: Virtual Spaces, Real Histories, Living Bodies, (ed) R. Shields, Sage Publications: London, 1996.

[21] Prown, J. Can the Farmer and the Cowman Still Be Friends? Learning from Things: Method and Theory of Material Culture Studies, (ed) W. Kingery Smithsonian Institution Press: Washington, 1996.

[22] Zyla, M. Controlling cyberporn soon may be a reality USA Today, $8^{\text {th }}$ April, p.15, 1998.

[23] Fox, R. Anthropology's Urban Progress Horizons of Anthropology, (ed) S. Tax \& L. Freeman, Aldine Publishing Company, Chicago, 1977. 